\title{
Early child L2 acquisition: Age or input effects? Neither, or both?*
}

\author{
SHARON UNSWORTH \\ Radboud University, Nijmegen \\ (Received I 8 December 2014-Revised 29 October 2015-Accepted 5 December 2015- \\ First published online 26 February 20I6)
}

\section{A BSTRACT}

This paper explores whether there is evidence for age and/or input effects in child $L_{2}$ acquisition across three different linguistic domains, namely morphosyntax, vocabulary, and syntax-semantics. More specifically, it compares data from English-speaking children whose age of onset to L2 Dutch was between one and three years with data from children whose age of onset was between four and seven years in their acquisition of verb morphology, verb placement, vocabulary, and direct object scrambling. The main findings were that there were no significant differences between the two groups in any of these areas and, with the exception of scrambling, current amount of exposure was the only factor significantly related to children's scores. The paper discusses the theoretical significance of these findings with respect to the role of input in the language acquisition process and the claim that there is a critical period ending within (early) childhood.

\section{INTRODUCTION}

One of the most robust findings in second language (L2) acquisition research is that there are age effects, that is, in the long term, L2 children typically outperform L2 adults, though whether these age effects take the form of a critical period remains controversial (see Muñoz \& Singleton, 20 I I, for a recent review). Generally, age effect studies in $\mathrm{L}_{2}$ acquisition compare $\mathrm{L}_{2}$ children with L2 adults, most usually when the children are already adults at testing. Whilst in this context various ages within childhood have been proposed as the age at which the ability to acquire an L2 to nativelike

[*] Earlier versions of this paper were presented at EUROSLA 24 at York University, at BUCLD 39, and at Mannheim University. I would like to thank audiences at all three for their useful comments, and in particular Holger Hopp and Jason Rothman. Thanks to two anonymous reviewers and the editors for their constructive feedback. Finally, thanks to all participating children, families, and schools, as well as the research assistants involved in data collection. Address for correspondence: Radboud University Nijmegen, Postbus 9103 Nijmegen6500HD, Netherlands. e-mail: s.unsworth@let.ru.nl 
levels starts to decline (e.g. age 7-8 years; Johnson \& Newport, I 989), until recently there has been little systematic investigation of the potential role of age of onset WITHIN childhood and its impact upon child L2 development.

Within this limited body of research, a number of studies have suggested that for certain aspects of morphosyntax, age effects may be observed at a (much) earlier age than proposed in previous literature. More specifically, it has been claimed that children whose age of onset is around age four or later acquire their $\mathrm{L}_{2}$ in a similar fashion to $\mathrm{L}_{2}$ adults and, crucially, in a fundamentally different way from the children whose age of onset is before this age (Kroffke \& Rothweiler, 2006; Meisel, 2008, 2009; Rothweiler, 2006; Sopata, 2010). For example, in his study on the acquisition of subject-verb agreement and clitic placement in first language $\left(\mathrm{L}_{\mathrm{I}}\right)$ German children acquiring French as L2, Meisel (2008) found that children whose age of onset was between three and four made errors typical of L2 adults, such as using subject-clitics with non-finite verbs. These findings are argued to be consistent with the notion of a critical (or sensitive) period for (certain aspects of) morphosyntax, ending around age four, after which nativelike acquisition (gradually) becomes impossible (see Meisel, 2009).

Similarly, Kroffke and Rothweiler (2006) and Rothweiler (2006) examined the acquisition of word order, subject-verb agreement, and subordinate clauses in $\mathrm{L}_{\mathrm{I}}$ Turkish children acquiring German as L2. These authors observed that the children whose age of onset was between three and four patterned similarly to monolingual $\mathrm{L}_{\mathrm{I}}$ children in terms of the developmental errors which they (did or did not) make, whereas those whose age of onset was older showed developmental patterns reminiscent of $\mathrm{L}_{2}$ adults. In short, then, whilst there is some variation in terms of the exact age of onset of the children involved, there are a number of studies on different $\mathrm{L}_{1} / \mathrm{L}_{2}$ combinations suggesting that there are age effects for certain aspects of morphosyntax in early childhood.

Whilst the longitudinal data analyzed in these studies provide a crucial insight into the developmental trajectories of their participants as they unfold, many of these studies involved a limited number of children only and they neglected to (systematically) take into account other factors known to vary with age of onset. As noted by Flege (2009), age of onset is a macro-variable which correlates with other factors including $L_{\mathrm{I}}$ proficiency, language dominance, frequency of $\left(\mathrm{L}_{\mathrm{I}} / \mathrm{L}_{2}\right)$ use, and kind of input (native vs. non-native). For claims about the existence of a critical period, age, that is, biological maturity, Is the crucial factor, however. This means that any assessment of the role of age of onset in early childhood should control for possible effects of these other factors before drawing conclusions about the possibility of a critical period. In this paper, we will attempt to do this by including estimations of input quantity (at the time of testing and over time) in our analyses of children's developing L2. 
There is a considerable body of literature demonstrating the impact of differential amounts of input on bilingual/L2 children's rate of acquisition (see Unsworth, in press, for a recent review). Variation in input quantity has been shown to be related to, amongst other things, vocabulary (e.g. Pearson, Fernández, Lewedeg \& Oller, I997; Thordardottir, 20 I I), verbal morphology (Nicoladis, Palmer \& Marentette, 2007; Paradis, 2010), nominal morphology (Thomas, Williams, Jones, Davies \& Binks, 2014), and grammatical gender (Gathercole \& Thomas, 2009; Unsworth, 20I3), as well as to more comprehensive assessments of children's grammatical abilities (Chondrogianni \& Marinis, 20 I ; Hoff, Core, Place, Rumiche, Senor \& Parra, 2012).

The number of studies examining input effects ACROss a range of linguistic domains within the same group of children is limited, however, and furthermore, the results of these studies are mixed. Thus, whilst several studies have found comparable relationships between input and rate of acquisition across domains, others have not. For example, in their study on English/Spanish bilingual toddlers, Hoff et al. (2012) observed similar patterns in the relationship between rate of acquisition and both vocabulary and grammar scores (on the CDI). Likewise, Paradis (20I I) observed that the same input factors, namely length of L2 English exposure and richness of the English environment, emerged as significant predictors of children's scores on vocabulary and verbal morphology (see also Bohman, Bedore, Pena, Mendez-Perez \& Gillam, 2010). These results contrast with those of Chondrogianni and Marinis (20 I I), who found that acquisition of vocabulary and complex syntax (i.e. passives, wh-questions) were affected by input factors, whereas the acquisition of verbal morphology was not. Likewise, Unsworth (2014) also found differences across domains: in her study of English/Dutch bilingual children aged four through seventeen, she observed that whereas amount of input was related to children's scores on grammatical gender, no such relation was observed with their acquisition of direct object scrambling, a property of Dutch involving the syntax-semantics interface.

Unsworth (2014) argued that because the information needed to acquire the meaning restrictions on scrambling is simply unavailable in the input (a 'poverty of the stimulus' problem), differences between bilingual children in terms of amount of exposure should be largely irrelevant, and hence no input effects are expected. She claimed that to fully understand the role of (variation in) input on children's developing language abilities, it is important to consider not only where input effects are expected but also where they are not, or at least where the role of input should be more minimal.

To date, there are only a handful of studies examining both the role of input and the role of age at the same time. In a cross-linguistic 6 Io 
comparison of the acquisition of grammatical gender by English/Dutch and English/Greek children with varying ages of onset, Unsworth, Argyri, Cornips, Hulk, Sorace, and Tsimpli (2014) found that amount of input was a significant predictor of children's accuracy scores in both Dutch and Greek, but age of onset was not. There were, however, some age-related differences in the Greek data: children with age of onset at birth were significantly more accurate on masculine and feminine nouns than children first exposed to Greek at age two or later. The authors related these cross-linguistic differences to the timing of acquisition in monolingual $\mathrm{L}_{\mathrm{I}}$ development (see also Tsimpli, 2014), which in turn they linked to the comparative opacity of the Dutch gender system when compared with the Greek (following Gathercole \& Thomas, 2005). Similarly, in a longitudinal study of the acquisition of French by Swedish-speaking children, Ågren, Granfeldt, and Thomas (2014) also observed input (quantity/quality) effects on later acquired target language properties (subject-verb agreement), whereas earlier acquired properties (finite/ non-finite verb forms) were more strongly related to age of onset than input. In short, there is reason to believe that age and input effects may interact with each other and therefore one should not be considered without the other.

Another factor which correlates with age of onset, again reflecting its status as a macro-variable (Flege, 2009), is $\mathrm{L}_{\mathrm{I}}$ proficiency. There is by now a considerable body of research demonstrating $L_{I}$ transfer effects in child L2 acquisition, especially but not exclusively in the domain of morphosyntax (e.g. Blom \& Baayen, 20I3; Chondrogianni, 2008; Unsworth, 2005; Zdorenko \& Paradis, 2008). Furthermore, under certain-as yet not completely understood-conditions, cross-linguistic influence is also attested in simultaneous bilingual language acquisition (see Serratrice, 2013, for review).

The goal of this paper is to draw together these various lines of research to test for both age effects and input effects in a range of linguistic domains in child L2 acquisition of Dutch, namely morphosyntax, lexicon, and syntaxsemantics. The specific properties tested are verb morphology and placement, receptive vocabulary, and direct object scrambling. We now briefly review previous research concerning possible age and input effects for the bilingual/child $\mathrm{L}_{2}$ acquisition of these particular properties in order to formulate some concrete predictions. Age effects in the present context are understood as differences between $\mathrm{L}_{2}$ children whose age of onset is before age four and $\mathrm{L}_{2}$ children whose age of onset is at age four or older. Input effects are understood as a significant relationship between variation in amount of exposure and L2 children's (developing) language abilities. 
We start with the domain of morphosyntax. Verbal inflection in Dutch is relatively impoverished. The present tense paradigm, illustrated in (I), consists of three forms: $-\varnothing,-t$, and $-e n$. There is a distinct infinitive form, marked by the suffix $-e n$, and this is homophonous with ${ }_{3} \mathrm{PL}$ finite forms. The focus of the present study is on the ${ }_{3} \mathrm{SG}$ and ${ }_{3} \mathrm{PL}$ contexts only.

$$
\begin{array}{lll} 
& \text { Singular } & \text { Plural } \\
\text { ISG } & \text { drink-ø } & \text { drink-en } \\
\text { 2SG } & \text { drink-t } & \text { drink-en } \\
\text { 3SG } & \text { drink-t } & \text { drink-en }
\end{array}
$$

Dutch is a verb-second (V2) language, which means that in declarative main sentences the finite verb always appears in second constituent position with any non-finite verbs in sentence-final position, as in (2a) (Koster, 1975). When some element other than the subject appears in sentence-initial position, for example, an adverbial (2b) or a topicalized object (2c), subject-verb inversion takes place.
a. Ik heb
gisteren
een
I have yesterday an
appel
gegeten
'I ate an apple yesterday.'

b. Gisteren heb ik een appel gegeten yesterday have I an apple eaten

'Yesterday I ate an apple.'
c. Een appel heb ik gisteren gegeten an apple have I yesterday eaten
'An apple, I ate yesterday.'

A number of studies have examined age effects in the child $\mathrm{L} 2$ acquisition of verb morphology and placement in Dutch and German (also a V2 language). The findings are mixed. Kroffke and Rothweiler (2006) and Sopata (2010) observed that children with an age of onset $(\mathrm{AO})$ of around four made the same errors as L2 adults, that is they produced non-finite forms in finite (V2) position, whereas children with an earlier age of onset did not, that is they patterned like monolingual Li children (see also Tran, 2005). These results contrast with Blom (2008), who found that L2 children with AO of four were highly accurate and did not produce non-finite -en forms in $\mathrm{V}_{2}$ position.

Sopata (2010) also observed that the three Li Polish children in her study acquiring L2 German systematically produced utterances with the finite verb in third rather than second position $\left(\mathrm{V}_{3}\right)$, illustrated in (3), whereas there was little evidence for such LI transfer in Blom's (2008) study of Li Turkish and 
Moroccan Arabic / Tarafit-speaking children (consistent with Meisel, 2008; but cf. Haznedar, i 997$)$.

*Gisteren ik heb een appel gegeten
yesterday I have an apple eaten
'Yesterday I ate an apple.'

In line with most (though not all) of the aforementioned studies, the prediction for the acquisition of verb morphology/placement is that there will be age effects, that is, we expect $\mathrm{L}_{2}$ children with age of onset at four or older to produce non-finite forms in finite positions and to produce $\mathrm{V}_{3}$ utterances, whereas children whose age of onset was before age four will do neither.

With respect to input effects, as noted above, various studies have observed bilingual/L2 children's rate of acquisition of verb morphology to be related to differences in amount of input (Blom, 2010). To the best of my knowledge, this relationship has yet to be addressed for the acquisition of $\mathrm{V}_{2}$, at least for bilingual/L2 children. Given that the evidence available in the input to the language-learning child that Dutch is a V2 language is rather limited, it is expected that input effects will be found for this property, too.

The rationale for this prediction is as follows. In an analysis of parental input to the monolingual Dutch-speaking child Hein in the CHILDES corpus, Yang (2002, p. 35) observed that whilst subject-initial main clause utterances such as (2a) predominated, appearing at a rate of $65 \%$, XVSO utterances as in (2b) and OVS utterances as in (2c), where the finite verb is clearly in second position, were much more infrequent $(34 \%$ and $\mathrm{I} \%$, respectively). For Yang, the crucial data were in fact the OVS utterances only, as on his parameter-setting approach this is the only word order to unambiguously distinguish Dutch as a V2 language from other languages, such as Hebrew. Yang proposed that because OVS utterances were so infrequent in the input, $L_{I}$ Dutch-speaking children would need some time to arrive at the correct parameter setting of $\mathrm{V}_{2}$, and he presented a reanalysis of the monolingual Dutch-speaking child Hein's data in support of his claim. The crucial observation for present purposes is that non-subject-initial utterances, that is, the evidence to the language-learning child that Dutch is a V2 language, constitute a relatively small part of the input. Extending Yang's observations to acquisitional settings where the input is significantly reduced, such as child L2 acquisition, one would expect this effect to (potentially) be more severe. In other words, input effects are also expected in the child L2 acquisition of $\mathrm{V}_{2}$ in Dutch.

The predictions for the acquisition of vocabulary are straightforward. Given that vocabulary acquisition continues into adulthood, there is in principle no reason to believe that there should be age effects in this 
domain. ${ }^{\mathrm{I}}$ As noted above, input effects are widely attested in the acquisition of vocabulary by bilingual/L2 children (e.g. Thordardottir, 20I I). Hence, the prediction for the present study is that we should find input but no age effects in the domain of vocabulary.

Finally, we turn to the acquisition of syntax-semantics, an area which has received little attention in the bilingual/child $\mathrm{L}_{2}$ acquisition literature (but see Sorace \& Serratrice, 2009). The property of Dutch to be investigated is direct object scrambling, and more particularly, the interpretive constraints on scrambled indefinite objects. In English, indefinite objects in negative sentences such as (4) are ambiguous and can thus be interpreted either specifically or non-specifically, that is, the sentence in (4) can be paraphrased as 'The boy didn't catch any fish' (non-specific interpretation) or 'There's a fish the boy didn't catch' (specific interpretation).

\section{(4) The boy didn't catch a fish}

In Dutch, these two interpretations are associated with different word orders, that is, indefinite objects in the scrambled position, as in $(5 \mathrm{~b})$, are interpreted specifically, whereas those which remain in their non-scrambled, or 'base' position within the verb phrase (VP), receive a non-specific interpretation, as in (5a); it is generally assumed that scrambling is the result of syntactic movement to some higher (VP-adjoined) position (de Hoop, I992), which position exactly is not important for the present discussion.
a. De jongen heeft geen (niet + een) vis gevangen (not $>a$ ) the boy has no not a fish caught 'The boy didn't catch a(ny) fish.'
b. De jongen heeft $\left[\begin{array}{ll}\text { een } & \text { vis }\end{array}\right]_{i}$ niet $t_{i}$ gevangen (a>not) the boy has a fish not caught
'There's a fish that the boy didn't catch.'

It is important to note that, in addition to indefinites, other types of objects (e.g. definite objects and pronouns) may also scramble, albeit without the same truth-conditional implications, and that scrambling occurs in conjunction with other (scope-taking) sentence adverbials besides negation, such as 'twice', and in these cases, no suppletive forms (such as geen in (5a)) are involved. Furthermore, scrambling of indefinites is highly infrequent, occurring in just 2\% (I9/I I 87) of cases (van Bergen \& de Swart, 2009).

Research has shown that L2 adults are able to acquire interpretive constraints on scrambling and comparable properties in other languages (Hopp, 2005; Marsden, 2009; Unsworth, 2005), and on the basis of this

\footnotetext{
I Golberg, Paradis, and Crago (2008) have shown that an older age of onset may in fact confer an advantage when it comes to rate of acquisition of vocabulary, but we will not consider this interpretation of age effects here.
} 
EARLY CHILD L2 ACQUISITION: AGE AND/OR INPUT EFFECTS?

TABLE I. How the acquisition of the interpretive constraints on scrambled indefinite objects in Dutch constitutes a poverty of the stimulus problem (following Pullum and Scholz’ (2002) specification schema)

I. ACQUIRENDUM

CHARACTERIZATION

Describe what is to be acquired

2. LACUNA SPECIFICATION

Identify set of sentences learner would need to access to acquire (I) on basis of input alone

3. INDISPENSABILITY ARGUMENT

Explain why (I) cannot be acquired without (2)

4. INACCESSIBILITY EVIDENCE

Show that (2) is not available to learner

5. ACQUISITON EVIDENCE

Show that (I) is indeed acquired
Scrambled indefinite objects restricted to specific interpretation.

Sentences containing scrambled indefinites in contexts where (i) availability of specific interpretation is apparent, and (ii) unavailability of non-specific interpretation is, too.

Indefinite objects are almost always non-specific, and non-scrambled.

Scrambled indefinites are incredibly rare. Other objects scramble more frequently but no such truth-conditional differences between scrambled and non-scrambled orders (van Bergen \& de Swart, 2009).

LI children restrict scrambled indefinites to specific interpretation by age six, as do (many) simultaneous bilingual children (Unsworth, 2014; Unsworth et al., 2008).

and other literature, it has been argued that there is no critical period for (compositional) semantics (Slabakova, 2006). The prediction for the present study is therefore that there will be no age effects within childhood for scrambling.

The predictions concerning input effects are as follows. If the acquisition of the interpretive constraints on scrambled indefinites constitutes a 'poverty of the stimulus' problem (Unsworth, 2005, 2014), no input effects are expected. The argument for the poverty of the stimulus for this particular property of Dutch is laid out in Table I, following the five criteria given by Pullum and Scholz (2002). Whilst these conditions are not entirely unproblematic (see for example Schwartz \& Sprouse, 20I3 for a critique), they are included here as they provide a systematic way to qualify the acquisition of certain linguistic properties as a poverty of the stimulus problem (but see Rothman \& Iverson, 20I I).

To sum up, if the information required to acquire the property in question is underdetermined by the input, then it should in principle not matter if the amount of input to which a child is exposed is reduced or varies. Table 2 presents a schematic overview of the predictions tested in the current study. 
TAB LE 2. Predictions for age and input effects across domains

\begin{tabular}{llll}
\hline Domain & Property & Age effects? & Input effects? \\
\hline Morphosyntax & Verb morphology & Yes & Yes \\
Lexicon & Verb placement & No & Yes \\
Syntax-semantics & Scrabulary & No & No \\
\hline
\end{tabular}

TABLE 3. Mean values (and standard deviations) for background and experiential variables

\begin{tabular}{lcc}
\hline Variable & Children with & Children with \\
& $\mathrm{AO}<4(n=44)$ & $\mathrm{AO} \geqslant 4(n=43)$ \\
\hline Age of onset & $2 ; 4(\mathrm{o} ; 8)$ & $5 ; 5(\mathrm{I} ; 3)$ \\
Age at time of testing & $7 ; 3(3 ; \mathrm{I})$ & $9 ; \mathrm{I}(2 ; \mathrm{I})$ \\
Current \% exposure & $34 \%(22)$ & $23 \%(22)$ \\
Traditional length of exposure (in years) & $5 ; 0(3 ; 4)$ & $3 ; 7(2 ; 4)$ \\
Cumulative length of exposure (in years) & $\mathrm{I} ; 5(\mathrm{I} ; 4)$ & $0 ; 9(\mathrm{I} ; 0)$ \\
\hline
\end{tabular}

\section{METHOD}

\section{Participants}

The participants in this study $(n=87)$ were children who had English as their first language $\left(\mathrm{L}_{\mathrm{I}}\right)$ and were learning Dutch as their second language (L2). English was the only (or main) language spoken at home and children had been exposed to this language from birth. All children were resident in the Netherlands at the time of testing, and twenty-two were born there. Exposure to Dutch was either from daycare or school, depending on the child's age, out-of-school activities, and/or the local environment. Children were divided into two age of onset (AO) groups, namely those whose age of onset was no earlier than one year and before age four years, and those whose age of onset was at age four but before age eight (Schwartz, 2004; Unsworth, 2005). Details of the participants' background and experiential variables are given in Table 3 . Traditional length of exposure was calculated in the usual fashion, i.e. by subtracting children's age of onset from their age at time of testing; CUMULATIVE length of exposure is a measure of exposure of time taking into account differences in amount of exposure of the years (see Unsworth, 2013, for more details).

Given the differences in age of onset, there are also inevitable differences in age at testing (see Muñoz, 2008, for relevant discussion). In general, children in both groups have comparatively more day-to-day exposure to English than to Dutch. In the $\mathrm{AO}<4$ group, three children attended Dutch-language daycare, twenty-four attended schools where Dutch was 
the main or only language of instruction, and the remaining seventeen children in this group attended schools where English was the main or only language of instruction. In the $\mathrm{AO} \geqslant 4$ group, thirteen children attended schools were Dutch was the main or only language of instruction and the remainder attended (predominantly) English-language schools with separate language classes in Dutch.

\section{Tasks and procedure}

Verb morphology and placement was tested using two elicited production tasks. The first task was designed to elicit data for both verb form and verb placement (Blom, Polišenskà \& Weerman, 2006/7; Polišenskà, 2010). Children were shown a picture of two people carrying out the same activity but with different objects, e.g. a man painting a door and a man painting a chair. The verb was introduced in the prompt in the infinitival form (Kijk! Deze twee plaatjes gaan over verven 'Look! These two pictures are about painting'), and the child was asked to tell the experimenter what was happening. For example, the experimenter started the sentence for the child with the subject (Deze man ... En die man ... 'This man ... And that man ...') and the child was expected to complete it (...verft een deur 'is painting a door' ... verft een stoel 'is painting a chair'). In total there were twenty-four items, all targeting the present simple tense, distributed evenly across ${ }_{3} \mathrm{SG}(n=\mathrm{I} 2)$ and ${ }_{3} \mathrm{PL}(n=\mathrm{I} 2)$ forms and three different word orders, namely subject-initial main clauses, non-subject-initial main clauses, and embedded clauses ( $n=8$ for each). The example given above illustrates the subject-initial main clause condition. In the non-subject-initial main clause, the prompt included an adverbial, $O p$ dit plaatje ... En op dat plaatje ... 'On this picture ... And on that picture ...', designed to force subject-verb inversion, i.e. verft de man een stoel. ${ }^{2}$ All the verbs were bisyllabic and had a stem ending on a sonorant or fricative; ${ }^{3}$ each verb was elicited four times, twice with a singular subject and twice with a plural subject. The selected verbs were aaien 'stroke', dromen 'dream', gooien 'throw', spelen 'play', dragen 'carry', geven 'give', kussen 'kiss', lezen 'read', verven 'paint', and wassen 'wash'. Items targeting grammatical gender were included as fillers (Unsworth, 2013).

${ }^{2}$ In the embedded clause condition, a boy looking through binoculars was introduced and the prompt included a main clause and complementizer which the child was expected to complete with an embedded clause, e.g., De man ziet dat ... 'The man sees that ...' followed by de man de stoel verft. In contrast to main clauses, the finite verb in embedded clauses appears in clause-final position. Children's acquisition of this particular property of Dutch will not be discussed in any detail in this paper.

${ }^{3}$ Blom, Vasic, and de Jong (2014) have shown that monolingual children are more likely to omit verbal inflection with stems ending on a plosive and hence these were avoided in the present study. 
For the assessment of children's verb morphology, children's responses were scored as percentage correct, that is, the number of target forms (main verb $+-t$ in ${ }_{3} \mathrm{SG}$ condition or main verb $+-e n$ in ${ }_{3} \mathrm{PL}$ condition) divided by the number of scorable responses (main verb $+-t$, main verb $+-e n$, and bare verbs). Reponses involving, for example, the past tense, the present continuous construction is/zijn aan het +infinitive, or the auxiliary gaat + infinitive were excluded from analysis.

For the assessment of children's verb placement, and more specifically their knowledge of $\mathrm{V}_{2}$, only responses in the non-subject-initial main clause condition were considered. Children's responses were scored as percentage correct, that is the number of responses with target word order (V2) divided by the number of scorable responses $\left(\mathrm{V}_{2}+\mathrm{V}_{3}\right)$. Responses where the subject was missing or where an auxiliary form was used instead of the main verb were excluded from analysis.

In the second elicited production task, children's knowledge of V2 was examined in a sentential context where a topicalized object appeared in sentence-initial position (cf. (2c)). This task was included because Tran (2005) found higher accuracy rates for production of $\mathrm{V}_{2}$ when the constituent in first position was a topicalized object rather than a $\mathrm{PP}$-adverbial, as is the case in the previous task. In this task, children were presented with a series of objects on cards and were asked questions about them by a puppet, Worp, who was introduced to the children as coming from outer space. The child's task was to help the puppet understand 'how things work on planet earth'. The child was first shown a picture and the puppet asked Wat is dat? 'What is that?' Once the child answered with the target object name, the puppet would repeat the name of the object as though she was hearing it for the first time and then she would ask a second question, namely $X$ ? Wat kun je met $X$ doen? 'X? What can you do with $\mathrm{X}$ ?', where $\mathrm{X}$ was the name of the object. The experimenter subsequently started the child's response with the object, i.e. Vertel 't even aan Worp. Aardbeien ... 'You tell Worp. Strawberries ...' using a rising intonation, and the child was expected to complete e.g. ... eet je 'lit: eat you' or kun je eten 'lit: can you eat'). There were no restrictions on the verb which the children were allowed to use in their responses. ${ }^{4}$

\footnotetext{
${ }_{4}$ As an anonymous reviewer points out, in elicitation tasks such as these children's responses may be categorized as incorrect not because they do not have the targeted knowledge but because they have failed to pick up on the experimenter's prompt, which in both tasks is crucial in order to create the required syntactic context for V2. Whilst we cannot of course rule out that children chose to ignore the prompt provided, every endeavour was made during testing to ensure that they did pay attention to it, for example in the instructions in the beginning ("I start (the sentence), and you finish it off"), and throughout testing if children for example started to respond without waiting for the experimenter to speak (“No, please wait. First I start, and then you finish.”).
} 
There were seven target items using the following objects: boeken 'books', een konijn 'a rabbit', een gitaar 'a guitar', melk 'milk', kleren 'clothes', appelsap 'apple juice', and een krant (a newspaper). 5 Six filler items showed pictures of different kinds of people and the child was expected to tell the puppet what each person did (e.g. Een tandarts ... 'A dentist' ...). The fillers were excluded from the present analysis. Children's responses were scored as percentage correct, that is, the number of responses with target word order ( $\left.\mathrm{V}_{2}\right)$ divided by the number of scorable responses $\left(\mathrm{V}_{2}+\right.$ $\left.\mathrm{V}_{3}\right)$. As in the first elicitation task, responses where the subject was missing were excluded from analysis. The data from this second task were not analyzed for verb morphology because in the context of subject-verb inversion used here, the $-t$ suffix is dropped in a $2 \mathrm{SG}$ context.

Vocabulary was assessed using the Dutch version of the Peabody Picture Vocabulary Task, PPVT-III-NL (Dunn, Dunn \& Schlichting, 2005). In this task, children are shown four pictures and asked to select the one which best represents a single word pronounced by the experimenter. The procedures given in the testing manual were followed. Standard scores (for monolinguals) are reported.

Scrambling was tested using a using a truth-value judgement task. In this task, based on Krämer (2000) and adapted further by Unsworth, Gualmini, and Helder (2008), children were presented with a story in which the main character manipulated two out of a set of three objects; for instance, a boy caught two out of three available fish in a pond. In other words, the scenario presented to the children was consistent with a specific interpretation of the relevant indefinite object (e.g. there was a fish that the boy did not catch) and inconsistent with a non-specific interpretation (i.e. it is not the case that the boy caught a fish). Subsequently, a puppet was asked to describe what had happened in the story and, in doing so, uttered a negative sentence containing a scrambled indefinite (cf. (5b)). The child's task was to judge the truthfulness of this statement. On the target-specific-interpretation, the expected answer is 'yes', whereas on the non-target-non-specific-interpretation, the expected answer is 'no'. Fillers $(n=8)$ were used to ensure that children could cope with true negatives, irrespective of their knowledge of scrambling. Accuracy scores were calculated for each child by dividing the number of target responses by the total number of items $(n=5)$.

\footnotetext{
5 The target objects were chosen on the basis of extensive piloting as those most likely to be known to children and those most likely to elicit a usable utterance. During the pilots we tried to restrict the verbs children produced to main verbs only but this proved to be impossible. For this reason, both auxiliary and main verbs are included in the analysis of this task. Unfortunately, this does mean that the data from the two elicitation tasks are not entirely comparable.
} 
Children were tested in each language in a separate session by a (near-) native-speaker research assistant. The sessions took place either at daycare/ school or at the child's home, depending on their age and the parents' wishes. All three tasks were part of a larger test battery and were always conducted in the following order: vocabulary, verb morphology/placement tasks in the order presented above, scrambling. For all tasks except vocabulary, the order of presentation of the test items was counterbalanced across children. Test sessions were videotaped and responses on the verb morphology/placement were later checked by a second experimenter. A randomly selected subset (approximately I0\%) were crosschecked by a second tester to calculate inter-rater reliability; the Kappa statistic was very high $(0.99, p<.00 \mathrm{I})$ indicating almost perfect agreement (Landis \& Koch, I 977).

\section{RESULTS}

For verb morphology and placement, children who consistently failed to include a subject or who consistently used alternatives were excluded (for verb form, this was 6 children in the $\mathrm{AO}<4$ group and 8 children in the $\mathrm{AO} \geqslant 4$, and for verb placement, Io and 8 children, respectively, in the first task (ADV in initial position), and I 4 and $\mathrm{I} 3$ children, respectively, in the second task (OBJ in initial position)). Alternative responses used an auxiliary or the present continuous construction aan het +infinitive. It is important to note that while such responses are uninformative for the present purposes, they are perfectly acceptable in the context, and they are also regularly produced by monolingual $L_{\mathrm{I}}$ children (Polišenskà, 2010); furthermore, despite not providing a response suitable for analysis in the present study, these responses also show that the children clearly understood the task.

In the scrambling task, children who demonstrated a response bias or who failed on more than 2 fillers, thereby showing a lack of understanding of true negatives, were excluded from the analysis ( 6 children in the $\mathrm{AO}<4$ group and 2 children in the $\mathrm{AO} \geqslant 4)$. Finally, for the vocabulary task, three children in the $\mathrm{AO}<4$ group were unable to complete the task following the standard procedure and hence had to be excluded from analysis. The results for all five outcomes are presented in Table 4.

An ANCOVA was carried out for each outcome variable separately with group $(\mathrm{AO}<4$ vs. $\mathrm{AO} \geqslant 4)$ as between-subjects factor and age at testing, (cumulative) length of exposure, and current amount of exposure as covariates. A main effect of group was interpreted as evidence for age effects, and when either of the two experiential variables was found to be a significant covariate, this was interpreted as evidence for input effects. The results for verb morphology and verb placement are presented in 620 
EARLY CHILD L2 ACQUISITION: AGE AND/OR INPUT EFFECTS?

TABLE 4. Mean scores (and standard deviations) for verb morphology (\% correct for $3 S G, 3 P L)$, verb placement (\% correct for $\left.V_{2}\right)$, vocabulary (standard score), and scrambling (\% scrambled indefinites interpreted specifically)

\begin{tabular}{|c|c|c|}
\hline Outcome & Children with $\mathrm{AO}<4$ & Children with $\mathrm{AO} \geqslant 4$ \\
\hline Verb morphology $-{ }_{3} \mathrm{SG}^{\mathrm{a}}$ & $78 \%(36 \%)$ & $70 \%(39 \%)$ \\
\hline Verb morphology $-{ }_{3} \mathrm{PL}^{\mathrm{a}}$ & $88 \%(25 \%)$ & $93 \%($ I $8 \%)$ \\
\hline Verb placement $-\mathrm{ADV}^{\mathrm{b}}$ & $69 \%(41 \%)$ & $48 \%(46 \%)$ \\
\hline Verb placement $-\mathrm{OBJ}^{\mathrm{b}}$ & $89 \%(21 \%)$ & $80 \%(38 \%)$ \\
\hline Vocabulary $^{\mathrm{c}}$ & $90(20)$ & $90(25)$ \\
\hline Scrambling $^{\mathrm{d}}$ & $90 \%(22 \%)$ & $96 \%(9 \%)$ \\
\hline
\end{tabular}

NOTES: ${ }^{\text {a }}$ number of main verbs with target morphology divided by number of scorable responses; ${ }^{\mathrm{b}}$ number of responses with target $\mathrm{V}_{2}$ order divided by number of scorable ( $\mathrm{V}_{2}$ $+\mathrm{V}_{3}$ ) responses; ${ }^{\mathrm{c}}$ standard score; ${ }^{\mathrm{d}}$ number of scrambled indefinite objects interpreted specifically divided by total number of items.

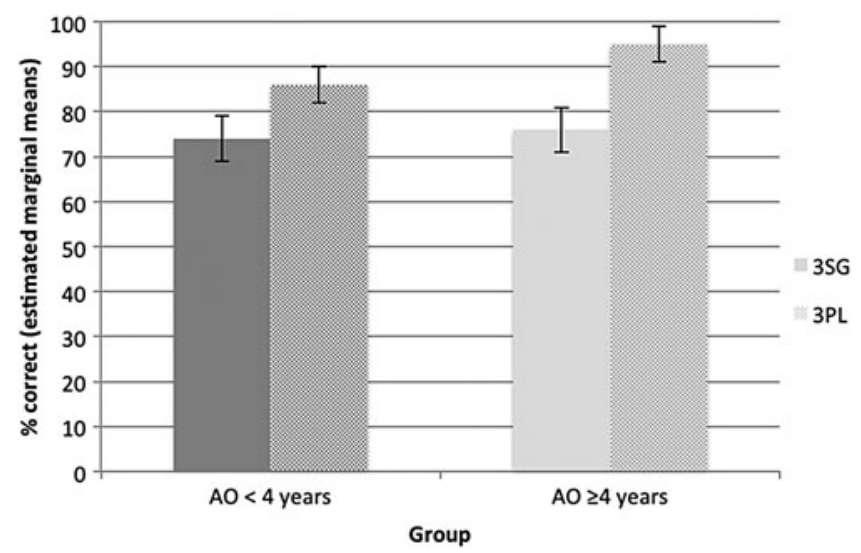

Fig. I. Verb morphology ( ${ }_{3} \mathrm{SG}$ and ${ }_{3} \mathrm{PL}$ ): percent correctly inflected verbs (estimated marginal means and standard error).

Figures I and 2; note that the plotted values are estimated marginal means and therefore differ from the values in Table 4. The estimated marginal means for vocabulary are $88\left(S E_{3}\right)$ for the $\mathrm{AO}<4$ group and $92\left(S E_{3}\right)$ for the $\mathrm{AO} \geqslant 4$ group; for scrambling, these are $9 \mathrm{I} \%(S E 3 \%)$ for the $\mathrm{AO}$ $<4$ group and $96 \%(S E 3 \%)$ for the $\mathrm{AO} \geqslant 4$ group.

There was no main effect of group for verb morphology (cf. Figure I), either for ${ }_{3} \mathrm{SG}(F(\mathrm{I}, 73)=0.07, p=\cdot 79)$ or ${ }_{3} \mathrm{PL}\left(F(\mathrm{I}, 73)=2 \cdot \mathrm{II}_{\mathrm{I}}, p=\cdot_{\mathrm{I}}\right)$, for verb placement (cf. Figure 2), either for $\operatorname{ADV}(F(\mathrm{I}, 69)=0 \cdot 26, p=.6 \mathrm{I})$ or OBJ $(F(\mathrm{~s}, 60)=0.55, p=\cdot 46)$, for vocabulary $(F(1,83)=0.74, p=.39)$, or 


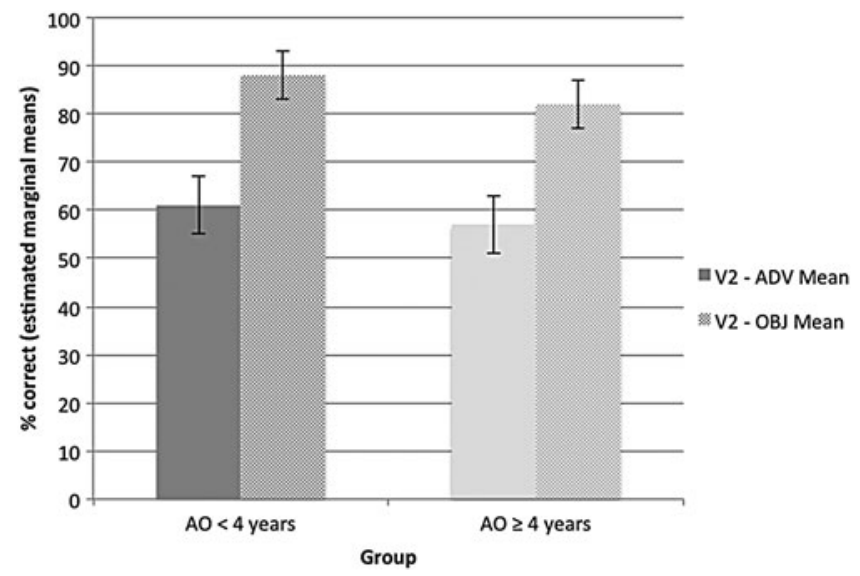

Fig. 2. Verb placement (with adverb (ADV) or topicalized object (OBJ) in initial position): percent verbs in $\mathrm{V}_{2}$ position (estimated marginal means and standard error).

for scrambling $(F(\mathrm{I}, 69)=0.93, p=\cdot 34)$. The covariate age at testing was not significantly related to children's scores on ${ }_{3} \mathrm{SG}(F(\mathrm{~s}, 73)=0 \cdot 80, p=\cdot 38)$, ${ }_{3} \mathrm{PL}(F(\mathrm{I}, 73)=0.03, p=.87)$, verb placement with $\operatorname{ADV}(F(\mathrm{~s}, 68)=0.40$, $p=.53)$ or OBJ $\left(F(\mathrm{I}, 60)=2.87, p=\cdot \mathrm{I}_{0}\right)$, vocabulary $\left(F\left(\mathrm{I}, 8_{3}\right)=0.38\right.$, $p=\cdot 54)$, or scrambling $\left(F(\mathrm{r}, 69)={ }_{\mathrm{I}} \cdot 78, p=.08\right)$. This was also the case for the covariate (cumulative) length of exposure: ${ }_{3} \mathrm{SG}(F(\mathrm{I}, 73)=0.2 \mathrm{I}$, $p=.65),{ }_{3} \mathrm{PL}(F(\mathrm{1}, 73)=0.04, p=.84)$, verb placement $\operatorname{ADV}(F(\mathrm{~s}, 69)=$ ०.30, $p=.59)$, verb placement $\mathrm{OBJ}(F(\mathrm{~s}, 60)=0 \cdot \mathrm{I} 6, p=.69)$, vocabulary $\left(F\left(\mathrm{r}, 8_{3}\right)=0.04, p=\cdot 8_{3}\right)$, or scrambling $\left(F(\mathrm{~s}, 69)={ }_{\mathrm{I}} \cdot 6_{5}, p=\cdot 20\right)$.

The covariate current amount of exposure was, however, significantly related to children's scores on ${ }_{3} \mathrm{SG}\left(F(\mathrm{I}, 73)=40 \cdot \mathrm{I}, p<\cdot 00 \mathrm{I}, \eta_{p}^{2}=\cdot 37\right),{ }_{3} \mathrm{PL}$ $\left(F(\mathrm{I}, 73)=3.86, \quad p=.0_{5}, \quad \eta_{p}^{2}=.0_{5}\right)$, verb placement $\operatorname{ADV}(F(\mathrm{I}, 69)=48 \cdot 4$, $\left.p<.00 \mathrm{I}, \eta_{p}^{2}=\cdot 43\right)$, verb placement $\mathrm{OBJ}\left(F(\mathrm{I}, 60)=\mathrm{I} 0.3, p=.002, \eta_{p}^{2}=\cdot \mathrm{I} 6\right)$, and vocabulary $\left(F(\mathrm{I}, 83)=\mathrm{I} 2 \cdot 9, p=.00 \mathrm{I}, \eta_{p}^{2}=\cdot \mathrm{I}_{4}\right)$, but not to their scores on scrambling $\left(F(\mathrm{I}, 69)=\mathrm{I}_{\mathrm{r}} \cdot 38, p=\cdot 25\right)$.

The analysis for verb form and verb placement has concentrated on respectively-proportion of verbs with the correct form irrespective of position, and proportion of verbs in the correct position irrespective of form. For a complete understanding of children's knowledge of verb morphology and placement, it is, however, crucial to also examine these two variables in tandem to determine whether finite forms appear in finite positions only. For this analysis, ${ }_{3} \mathrm{SG}$ only responses are used as the correct form of the plural verb is homophonous with the infinitive (e.g. $z e$ verven 'they paint' and verven 'to paint'), which means that correctly inflected (finite) forms of the verb are indistinguishable from incorrect 
EARLY CHILD L2 ACQUISITION: AGE AND/OR INPUT EFFECTS?

TAB LE 5. Contingency table for verb form and placement (number of responses)

\begin{tabular}{|c|c|c|c|c|c|}
\hline & & \multicolumn{2}{|c|}{$\begin{array}{l}\text { Children with } \\
\mathrm{AO}<4\end{array}$} & \multicolumn{2}{|c|}{$\begin{array}{l}\text { Children with } \\
\mathrm{AO} \geqslant 4\end{array}$} \\
\hline & & $\mathrm{V}_{2}$ & $\mathrm{~V}_{3}$ & $\mathrm{~V}_{2}$ & $\mathrm{~V}_{3}$ \\
\hline \multirow[t]{2}{*}{ Form } & Finite & 75 & 23 & 88 & 57 \\
\hline & Non-finite & $\circ$ & I 5 & $\circ$ & 46 \\
\hline
\end{tabular}

NOTES: $\mathrm{AO}=$ age of onset; $\mathrm{V}_{2}=$ finite verb in second constituent position; $\mathrm{V}_{3}=$ finite verb in third constituent position.

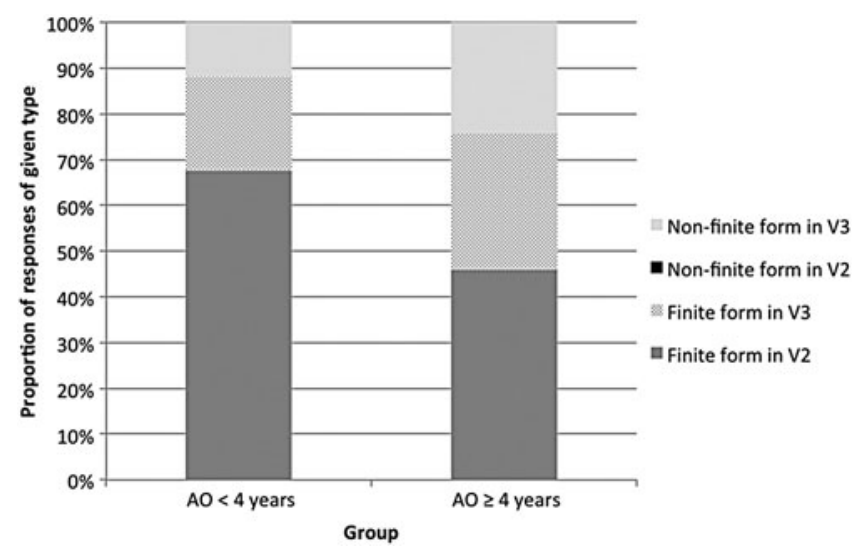

Fig. 3. Verb form and placement: error types. Proportion of responses within group of given type.

(non-finite) forms. Children's responses in the ${ }_{3} \mathrm{SG} / \mathrm{V} 2$ condition were classified as belonging to one of the following four categories: non-finite form in $V_{3}$ position (6a), non-finite form in $V_{2}$ position (6b), finite form in $\mathrm{V}_{3}$ position (cf. (3)), and finally, the only correct response, namely finite form in $\mathrm{V}_{2}$ position (cf. (2b)).

a. *Op dit plaatje de man verven een deur on this picture the man paint a door

b. *Op dit plaatje verven de man een deur on this picture paint the man a door

The results are presented as raw figures in Table 5 and as proportions in Figure 3 .

When children made errors, these were errors of placement only, or placement and form, that is, when children failed to produce a target finite form in $\mathrm{V}_{2}$ position, they produced either a finite or a non-finite form in $\mathrm{V}_{3}$ position. 
There were no children (in either group) who produced non-finite forms in V2 position. An analysis of the individual children's results reveal that the non-finite forms in $\mathrm{V}_{3}$ position are produced by six (out of thirty-five) children with $\mathrm{AO}<4$ (two with one token, one with two tokens, one with three tokens, and two with four tokens) and twelve (out of thirty-five) children with $\mathrm{AO} \geq 4$ (four with two tokens, four with three tokens, and four with four tokens). Finite forms in $\mathrm{V}_{3}$ position were produced by twelve children with $\mathrm{AO}<4$ (four with one token, six with two tokens, one with

three tokens, and one with four tokens) and by fifteen children with $\mathrm{AO} \geq 4$ (four with one token, seven with two tokens, and four with four tokens).

\section{DISCUSSION}

In this paper, we presented data from English-speaking children acquiring Dutch as an $\mathrm{L}_{2}$ in order to investigate the role of age of onset and input quantity in (early) child L2 acquisition. Children were divided into two age groups, those whose age of onset was between the ages of one and three years and those whose age of onset was between the ages of four and seven years. Three different linguistic domains were targeted: children's knowledge of verb morphology and verb placement (morphosyntax) was examined using two elicited production tasks, vocabulary was tested using the standardized, receptive PPVT task (in Dutch), and the interpretation of scrambled indefinite objects (syntax-semantics) was accessed using a truth-value judgement task.

Our first prediction was that, for verb morphology and placement, there would be age effects and input effects. The results indicated no significant differences between the two groups on either verb morphology or placement, irrespective of the type of constituent in initial position (ADV or OBJ). In other words, once age at testing, (cumulative) length of exposure, and current amount of exposure were controlled for, the children whose AO was four years or older did not produce significantly more errors than children whose $\mathrm{AO}$ was younger than four years, despite having had less exposure to Dutch overall. Moreover, children in both groups produced similar types of errors, namely finite and non-finite forms in $\mathrm{V}_{3}$ position. The covariate current amount of exposure was significantly related to children's accuracy scores and explained $37 \%$ of the variance in the data for ${ }_{3} \mathrm{SG}, 5 \%$ of the variance for $3 \mathrm{PL}, 43 \%$ of the variance for verb placement with an adverbial in initial position, and $16 \%$ of the variance for verb placement with an object in initial position. In short, then, our prediction concerning input effects in the domain of morphosyntax was borne out, whereas our prediction for age effects was not.

The production of $\mathrm{V}_{3}$ is often classified as an error which is typical for $\mathrm{L}_{2}$ adults and, as such, in previous work has been used to argue that L2 children 624 
$(\mathrm{AO} \geqslant 3)$ pattern like $\mathrm{L}_{2}$ adults rather than $\mathrm{L}_{\mathrm{I}}$ children (Sopata, 2010). Given that children in the younger AO group also made these types of errors, albeit to a lesser degree, the same line of argumentation cannot be used here. If it were, then one would have to claim that the relevant age at which a purported critical period should end is earlier than around age four.

There are two possible (and not mutually exclusive) explanations for children's production of $\mathrm{V}_{3}$ utterances. The first is that, in the first elicitation task, participants produced more $\mathrm{V}_{3}$ utterances than they may otherwise have done as a result of the probe employed in the task. Recall that in this task the children were presented with two pictures of people carrying out the same activity but with different objects; in the non-subject-initial main clause condition the experimenter started the utterance for the child with the adverbial $O p$ dit plaatje ... Op dat plaatje ... 'On this picture ... On that picture ...'. We cannot rule out the possibility that the children failed to pick up on this cue and simply proceeded with what for them was a subject-initial main clause. This does, however, seem unlikely: data from monolingual four- to seven-year-old children $(n=3 \mathrm{I})$ using the same task contained just three such tokens, i.e. finite forms in $\mathrm{V}_{3}$ position, produced by two different children. If the $\mathrm{L}_{2}$ children produced more $\mathrm{V}_{3}$ utterances as the result of a methodological artefact, one would expect the monolingual children to do this, too, but they did not.

Rather than a methodological artefact, it is the bilingual/L2 children's other language, English, which may be the source of their non-target $\mathrm{V}_{3}$ responses, at least in the first elicitation task. This would be in line with several studies showing robust transfer effects in child L2 acquisition of word order (e.g. Mobaraki, Vainikka \& Young-Scholten, 2008; Unsworth, 2005). It is also possible that these errors may be due to limited proficiency in or exposure to Dutch. At this stage, there is no way to tease apart these two possibilities.

On the whole, children were more targetlike in their production of $\mathrm{V}_{2}$ on the task where the finite verb was preceded by an object in sentence-initial position than on the task where the finite verb was preceded by a PP-adverbial. This is in line with Tran (2005), who also found that $\mathrm{L}_{\mathrm{I}}$ English children acquiring German were more accurate in the production of $\mathrm{V}_{2}$ in contexts with a topicalized object than in contexts with a preposed PP-adverbial. There are (at least) two possible explanations for the observed difference in children's production of $\mathrm{V}_{2}$ in these two different contexts. The first is that this may simply be due to the type of data elicited: main verbs in ${ }_{3} \mathrm{SG}$ and ${ }_{3} \mathrm{PL}$ contexts in the $\mathrm{ADV}$ task versus main and auxiliary/modal verbs in $2 \mathrm{SG}$ contexts in the OBJ task. For example, it may be easier to produce the verb in the correct place in a context where inflection has to be dropped, as is the case for verbs with a 
postverbal $2 \mathrm{SG}$ subject in the $\mathrm{OBJ}$ task, rather than in a context where inflection is obligatory, as is the case for ${ }_{3} \mathrm{SG}$. The second is that it is also possible that the lower scores in the adverbial-initial context reflect an increased likelihood of transfer from English in this context. It would seem that English PP-adverbials, such as On Monday, are more likely to appear in sentence-initial position than topicalized objects, and this in turn may mean that crosslinguistic influence is more likely in a comparable context in Dutch.

A final noteworthy observation concerning verb form and placement is the fact that none of the children, in either group, used non-finite forms in $\mathrm{V}_{2}$. This is in line with $\mathrm{L}_{2}$ children with $\mathrm{L}_{\mathrm{I}}$ Turkish and Moroccan Arabic / Berber in Blom (2008), but contrasts with other studies such as Tran (2005) and Rothweiler (2006). In this sense, the L2 children in the present study pattern more like $\mathrm{L}_{\mathrm{I}}$ children in their acquisition of verb morphology, but they are more like L2 adults in their verb placement in that they use $\mathrm{V}_{3}$ word order, as Sopata (2010) also found for the $\mathrm{L}_{2}$ German children in her study. ${ }^{6}$

The predictions for vocabulary were that children's scores were not expected to differ across $\mathrm{AO}$ groups but they were expected to be related to the input variables. Both these predictions were borne out. Once age at testing, (cumulative) length of exposure, and current amount of exposure were controlled for, there was no significant difference between the $\mathrm{AO}<4$ and the $\mathrm{AO} \geqslant 4$ groups in their scores on the standardized vocabulary task. Current amount of exposure was, however, significantly related to their scores and explained $14 \%$ of the variance. The observation that amount of input is a significant predictor of children's vocabulary scores is in line with previous literature on bilingual/L2 children (e.g. Hoff et al., 2012; Pearson et al., I997; Thordardottir, 20 I I).

It is noteworthy that while there is quite some variation in children's scores, scores for both groups are quite high: both groups have a standard score of on average 90 , which means that they fall within age-appropriate monolingual norms. This is all the more surprising given that children in both groups have rather limited exposure to Dutch, namely on average $34 \%$ in the $\mathrm{AO}<4$ group and $23 \%$ in the $\mathrm{AO} \geqslant 4$ group. Taken together with the comparatively small effect size $\left(\eta_{p}^{2}=\cdot_{\mathrm{I}} 7\right)$, these results suggest that other factors are likely to be at play in these data. One such factor may be the typological similarity between English and Dutch, which means that children may have been able to make use of cognates to arrive at the target response on the vocabulary task. Whilst a detailed analysis of the cognate vs. non-cognate items goes beyond the scope of this paper, studies on

\footnotetext{
${ }^{6}$ The children in Sopata's (2010) study produced non-finite forms in $\mathrm{V}_{3}$, though, which both monolingual children and the children in the present study do not do.
} 
other bilingual/L2 populations suggest that the availability of cognates may indeed impact upon children's vocabulary scores and should be taken into account when comparing results across studies (e.g. Dijkstra, 20I3; Stadthagen-González, Gathercole, Pérez-Tattam \& Yavas, 2013).

We now turn to the domain of syntax-semantics. No age effects were predicted and this prediction was borne out. The finding that the children with $\mathrm{AO} \geqslant 4$ performed similarly to children with $\mathrm{AO}<4$ is in line with Slabakova (2006), who argues that there is no critical period for (compositional) semantics, as well as with a large body of literature demonstrating that $\mathrm{L}_{2}$ adults are able to acquire targetlike knowledge of a range of linguistic phenomena at the syntax-semantics interface.

With respect to input, it was argued that the acquisition of the interpretive constraints on scrambled indefinite objects constitutes a poverty of the stimulus problem (Unsworth, 20I4), and consequently no input effects were predicted. In line with this prediction, children's scores on the truth-value judgement task were neither related to current amount of exposure nor to cumulative length of exposure. In fact, children in both groups scored almost at ceiling, indicating target knowledge of this particular property of Dutch, despite their rather limited exposure to Dutch.

There is, however, a potentially complicating factor in this analysis, namely the (unpredicted) possibility of transfer from English in this particular experimental context. Whilst indefinite objects in negative sentences (cf. (4)) are in principle ambiguous, when we examined data from a task in English comparable to the one reported on here for Dutch (based on Miller \& Schmitt, 2004), we found that most children showed a preference for the specific interpretation. We therefore cannot rule out the possibility that when children allowed the specific interpretation in Dutch, they did so because they transferred their preferred interpretation from English, rather than because they were employing targetlike knowledge of Dutch.

There is nevertheless reason to believe that $\mathrm{L}_{\mathrm{I}}$ transfer cannot be the whole story. When we compare children's response patterns on the Dutch and English tasks, we find evidence to suggest that they Do differentiate their interpretations across the two languages. Whilst the vast majority of children (55/69) (almost) always accepted the specific reading in both languages, almost all of the children ( I I/I 4) who had a different response pattern in their two languages allowed an interpretation in English (non-specific) which they did not appear to allow in Dutch, or which they at least allowed less frequently. In a study with a larger group of simultaneous bilingual children (Unsworth, 20I4), similar tendencies were observed. Thus, whilst the results concerning children's knowledge of scrambling are less clear-cut than they appeared at first blush, the fact that children differentiated their responses in English and Dutch in this way 
TABLE 6. Findings for age and input effects across domains

\begin{tabular}{llll}
\hline Domain & Property & Age effects? & Input effects? \\
\hline Morphosyntax & Verb morphology & No & Yes \\
Lexicon & Verb placement & No & Yes \\
Syntax-semantics & Vocabulary & No & No \\
\hline
\end{tabular}

suggests that when they accepted the target-specific interpretation in Dutch, they did not necessarily do so as a result of $\mathrm{L}_{\mathrm{I}}$ transfer. In other words, they appear to have overcome the poverty of the stimulus (see Unsworth, 2014, for an account of how they exactly they might do this). A summary of the findings across all three domains for both age and input is provided in Table 6 .

Comparing results across different domains, the present study provides little evidence for age effects in (early) child L 2 acquisition, including in domains where they have been observed in previous studies, for example for verbal morphology/placement. One reason for this might be that, in contrast to most of the earlier studies (e.g. Rothweiler, 2006), this study also takes into account factors which co-vary with age of onset, such as input quantity. It is, however, important to bear in mind that failing to find a significant difference between groups does not mean that we can say that there is evidence AGAINST age of onset effects; there may be a multitude of reasons for why such a difference was not found. All we can say at this stage is that for the target language properties and two groups of children here, no significant differences were observed. It is worth noting, however, that similar findings obtain when the dividing line between the two groups is drawn at age three or at age six (Meisel, 2009; Sopata, 2010), and when the age of onset is included as a continuous variable in a regression analysis, that is, there remain no significant differences between the two groups and age of onset is not a significant predictor. An alternative approach, which may more readily detect age of onset effects, should they exist, might be to compare more differentiated groups, for example a group of children whose age of onset is between two and three years with a group of children whose age of onset is between six and seven years. Unfortunately, there are not enough children in the present dataset to carry out such an analysis. ${ }^{7}$

In the present study, children's scores for verb morphology, verb placement, and vocabulary were significantly related to their current amount of exposure. This finding underscores the importance of treating

7 I thank Jesse Snedeker for drawing this possibility to my attention. 
age of onset as a macro-variable (Flege, 2009,) and including variation in, for example, input quantity and quality in any analysis of age effects in (early) childhood. Given that input quantity and quality (in part inevitably) vary between children who start acquiring their L2 earlier and children with an older age of onset, it is essential to control for these variables before concluding that age is the crucial factor. Similarly, for a complete picture of input (or age) effects in early child L2/bilingual acquisition, it is necessary to examine linguistic domains where such effects are expected, and crucially where they are not. Whilst further research is necessary to (dis)confirm the pattern of findings observed here, the present study illustrates the need to go beyond target language properties such as verb morphology and vocabulary and examine more complex syntactic phenomena, and/or phenomena which involve interaction between different domains.

Finally, let us consider the theoretical implications of the present study's findings. In several studies examining the relationship between variation in input and bilingual children's language outcomes, the existence of input effects has been argued to support a usage-based (or constructivist) approach to language acquisition (e.g. Gathercole, 2007; Hammer, Komaroff, Rodriguez, Lopez, Scarpino \& Goldstein, 2012; Hoff et al., 20I2; Paradis, Nicoladis, Crago \& Genesee, 20I I). Indeed, the findings for verb morphology, verb placement, and vocabulary in this study are consistent with such an approach. Oversimplifying somewhat, the general idea is that if language is acquired in a piecemeal fashion on the basis of the input, we can expect an effect of relative amount of input for bilingual children across different domains, and crucially in the acquisition of grammar/morphosyntax as well as in the acquisition of vocabulary.

Whilst the logic of this argument is undisputed, it is worth noting that, as yet, the focus of much of the research in this area has been on linguistic properties such as verbal morphology and vocabulary, that is, properties where input effects would be expected on any approach to (bilingual/ second) language acquisition. Expanding the domain of enquiry to (complex) properties where input severely underdetermines the knowledge children acquire, as well as explaining why input effects are not always found is an important-and arguably, crucial-step in implementing this approach to the language development of bilingual/L2 children (see e.g. Goldberg, Casenhiser \& Sethuraman, 2004, for one proposal concerning monolingual children and O'Grady, 20I3, on L2 acquisition).

The present study's finding that, despite the relative infrequency of indefinite objects in scrambled position, (at least some) L2 children come to know that these are restricted to a specific interpretation, is arguably hard to reconcile with a usage-based approach to bilingual acquisition, such as for example that of Gathercole (2007). It is, however, in principle 
consistent with the nativist approach, where this acquisitional task constitutes a 'poverty of the stimulus' problem (Unsworth, 2014). The observation that there are input effects for verb morphology and placement are also consistent with this approach (see Yang, 2002, on V2, for example). However, to more thoroughly test differences between these two approaches, much more specific predictions are required, especially from a nativist perspective, where variation in input and its impact on the developmental process has only recently started to be taken (more) seriously (see, e.g. Miller \& Schmitt, 20ı 2; Omaki \& Lidz, in press; Yang, 2002; cf. Blom, Paradis \& Sorenson Duncan, 2012, for a recent demonstration of to the child $\mathrm{L}_{2}$ acquisition of verb morphology within a usage-based approach).

There are a number of limitations to the present study. First, it included a range of linguistic domains, but the number and type of phenomena investigated nevertheless were quite limited. For example, vocabulary was examined using a receptive one-word standardized task only. Furthermore, the tasks used for each of the three target phenomena were different (elicited production, receptive standardised task, truth-value judgement); for completely comparable data, similar methodologies should be employed in future studies. ${ }^{8}$ The analysis of input effects was limited to input quantity only; it is likely that differences in input quality will also impact on children's L2 development (Unsworth, in press). Finally, as discussed in detail above, the interpretation of the scrambling data were complicated by the possible role of $\mathrm{L}_{\mathrm{I}}$ transfer. Once again, additional research is needed to address this issue.

\section{CONCLUSION}

The present findings suggest that input (quantity) is an important factor in (early) child $\mathrm{L}_{2}$ acquisition, and in the context of the English/Dutch children studied here, it appears to be more important than age of onset. Nevertheless, input effects were not observed across the board, and where they were observed they were not equally large. Across domains, crosslinguistic influence (or transfer) from the children's other language, English, contributed to the some of the observed response patterns,

\footnotetext{
${ }^{8}$ As pointed out by an anonymous reviewer, the different domains are not all investigated using the same modality in the present study: lexical (vocabulary) and syntactic-semantic (scrambling) knowledge were assessed using receptive skills and morphosyntactic knowledge (verb form and placement) using productive tasks. Assuming that both receptive and productive skills reflect the deployment of underlying linguistic knowledge, and that this is what is affected by the factors tested here, namely age of onset and input quantity, it seems unlikely that differences in task modality can account for the study's findings (see Paradis, 2010, for relevant discussion). However, we cannot rule out that other tasks may lead to different results.
}

$$
630
$$


sometimes in non-negligible ways. Taken together, these findings reiterate the need for a more multi-faceted approach to age effects in child L2 acquisition, whereby the influence of factors known to covary with age of onset is ruled out before concluding that biological maturity is a (or even THE) key determinant of children's second language acquisition.

\section{REFERENCES}

Ågren, M., Granfeldt, J. \& Thomas, A. (20I4). Combined effects of age of onset and input on the development of different grammatical structures: a study of simultaneous and successive bilingual acquisition of French. Linguistic Approaches to Bilingualism 4, 462-93.

Blom, E. (2008). Testing the domain-by-age model: inflection and placement in Dutch verbs. In B. Haznedar \& E. Gavruseva (eds), Current trends in child second language acquisition: a generative perspective, 27 I-300. Amsterdam: John Benjamins.

Blom, E. (20 Iо). Effects of input on the early grammatical development of bilingual children. International Fournal of Bilingualism 14, 422-46.

Blom, E. \& Baayen, H. R. (2013). The impact of verb form, sentence position, home language, and second language proficiency on subject-verb agreement in child second language Dutch. Applied Psycholinguistics 34, 777-8 I I.

Blom, E., Paradis, J. \& Sorenson Duncan, T. (2012). Effects of input properties, vocabulary size, and $\mathrm{L}_{\mathrm{I}}$ on the development of third person singular $-s$ in child L2 English. Language Learning 62, 965-94.

Blom, E., Polišenskà, D. \& Weerman, F. (2006/7). Variation in inflection: a comparison of agreement inflection in child Li, child L2 and adult L2 Dutch. Morphology 16, 3 I 3-36.

Blom, E., Vasic, N. \& de Jong, J. (20I4). Production and processing of subject-verb agreement in monolingual Dutch children with specific language impairment. Fournal of Speech, Language, and Hearing Research 57, 952-65.

Bohman, T. M., Bedore, L. M., Pena, E. D., Mendez-Perez, A. \& Gillam, R. B. (2010). What you hear and what you say: language performance in Spanish-English bilinguals. International Fournal of Bilingual Education and Bilingualism 13, 325-44.

Chondrogianni, V. (2008). Comparing child and adult L2 acquisition of the Greek DP: effects of age and construction. In B. Haznedar \& E. Gavruseva (eds), Current trends in child second language acquisition: a generative perspective, 97-I42. Amsterdam: John Benjamins.

Chondrogianni, V. \& Marinis, T. (20 I I). Differential effects of internal and external factors on the development of vocabulary, tense morphology and morpho-syntax in successive bilingual children. Linguistic Approaches to Bilingualism I, 31 8-42.

de Hoop, H. (1992). Case configuration and noun phrase interpretation. PhD dissertation, published (I 996). New York: Garland.

Dijkstra, J. (20I3). Growing up with Frisian and Dutch: the role of language input in the early development of Frisian and Dutch among preschool children in Friesland. Unpublished PhD dissertation, University of Amsterdam.

Dunn, L. M., Dunn, L. M. \& Schlichting, L. (2005). Peabody Picture Vocabulary Test-III-NL. Amsterdam: Pearson.

Flege, J. E. (2009). Give input a chance! In T. Piske \& M. Young-Scholten (eds), Input matters in SLA, 175-90. Clevedon: Multilingual Matters.

Gathercole, V. C. M. (2007). Miami and North Wales, so far and yet so near: Constructivist account of morpho-syntactic development in bilingual children. International fournal of Bilingual Education and Bilingualism 10, 224-46.

Gathercole, V. C. M. \& Thomas, E. M. (2005). Minority language survival: input factors influencing the acquisition of Welsh. In J. Cohen, K. McAlister, K. Rolstad \& J. MacSwan (eds), Proceedings of the 4th International Symposium on Bilingualism, 85274. Somerville, MA: Cascadilla Press. 
Gathercole, V. C. M. \& Thomas, E. M. (2009). Bilingual first-language development: dominant language takeover, threatened minority language take-up. Bilingualism: Language and Cognition 12, 2 I 3-37.

Golberg, H., Paradis, J. \& Crago, M. (2008). Lexical acquisition over time in minority LI $_{\mathbf{I}}$ children learning English as L2. Applied Psycholinguistics 29, 4I-65.

Goldberg, A. E., Casenhiser, D. M. \& Sethuraman, N. (2004). Learning argument structure generalizations. Cognitive Linguistics r5, 289-3 I 6 .

Hammer, C. S., Komaroff, E., Rodriguez, B. L., Lopez, L. M., Scarpino, S. E. \& Goldstein, B. (2012). Predicting Spanish-English bilingual children's abilities. Fournal of Speech, Language, and Hearing Research 55, $125 \mathrm{I}-64$.

Haznedar, B. (1997). Child L2 acquisition of English: a longitudinal case study of a Turkish-speaking child. Unpublished PhD dissertation, University of Durham.

Hoff, E., Core, C., Place, S., Rumiche, R., Senor, M. \& Parra, M. (2012). Dual language exposure and early bilingual development. Fournal of Child Language 39, I-27.

Hopp, H. (2005). Constraining second language word order optionality: scrambling in advanced English-German and Japanese-German interlanguage. Second Language Research 21, 34-7 I.

Johnson, J. S. \& Newport, E. L. (r 989). Critical period effects in second language learning: the influence of maturational state on the acquisition of English as a second language. Cognitive Psychology 21, 60-99.

Koster, J. (1975). Dutch as an SOV language. Linguistic Analysis r, I I I-36.

Krämer, I. (2000). Interpreting indefinites: an experimental study of children's language comprehension. Unpublished PhD dissertation, Utrecht University.

Kroffke, S. \& Rothweiler, M. (2006). Variation im frühen Zweitspracherwerb des Deutschen durch Kinder mit türkischer Erstsprache [Variation in early second language acquisition of German by children with Turkish as $\mathrm{LI}_{\mathrm{I}}$. In M. Vliegen (ed.), Proceedings of the 39th Linguistics Colloquium (pp. I 45-1 53). Amsterdam: Peter Lang.

Landis, J. R. \& Koch, G. G. (I 977). The measurement of observer agreement for categorical data. Biometrics 33, I 59-74.

Marsden, H. (2009). Distributive quantifier scope in English-Japanese and Korean-Japanese interlanguage. Language Acquisition r6, I35-77.

Meisel, J. M. (2008). Child second language acquisition or successive first language acquisition? In B. Haznedar \& E. Gavruseva (eds), Current trends in child second language acquisition, 55-80. Amsterdam: John Benjamins.

Meisel, J. M. (2009). Second language acquisition in early childhood. Zeitschrift Für Sprachwissenschaft 28, 5-34.

Miller, K. \& Schmitt, C. (2004). Wide-scope indefinites in English child language. In J. Van Kampen \& S. Baauw (eds), Proceedings of Generative Approaches to Language Acquisition 2003, 3 I 7-28. Utrecht: LOT Occasional Series.

Miller, K. \& Schmitt, C. (20I2). Variable input and the acquisition of plural morphology. Language Acquisition 19, 223-6I.

Mobaraki, M., Vainikka, A. \& Young-Scholten, M. (2008). The status of subjects in early child L2 English. In B. Haznedar \& E. Gavruseva (eds), Current trends in child second language acquisition: a generative perspective, 209-36. Amsterdam: John Benjamins.

Muñoz, C. (2008). Symmetries and asymmetries of age effects in naturalistic and instructed L2 learning. Applied Linguistics 29, 578-96.

Muñoz, C. \& Singleton, D. (201 I). A critical review of age-related research on L2 ultimate attainment. Language Teaching 44, I-35.

Nicoladis, E., Palmer, A. \& Marentette, P. (2007). The role of type and token frequency in using past tense morphemes correctly. Developmental Science ro, 237-54.

O'Grady, W. (2013). The illusion of language acquisition. Linguistic Approaches to Bilingualism 3, 253-86.

Omaki, A. \& Lidz, J. (in press). Linking parser development to acquisition of syntactic knowledge. Language Acquisition.

Paradis, J. (2010). Bilingual children's acquisition of English verb morphology: effects of language exposure, structure complexity, and task type. Language Learning 6o, 65 I-80. 


\section{EARLY CHILD L2 ACQUISITION: AGE AND/OR INPUT EFFECTS?}

Paradis, J. (20II). Individual differences in child English second language acquisition: comparing child-internal and child-external factors. Linguistic Approaches to Bilingualism I, 2 I $3-37$.

Paradis, J., Nicoladis, E., Crago, M. \& Genesee, F. (20 I I). Bilingual children's acquisition of the past tense: a usage-based approach. Fournal of Child Language $\mathbf{3 8}, 544-78$.

Pearson, B. Z., Fernández, S. C., Lewedeg, V. \& Oller, D. K. (I997). The relation of input factors to lexical learning by bilingual infants. Applied Psycholinguistics r8, 4I-58.

Polišenskà, D. (2010). Dutch children's acquisition of verbal and adjectival inflection. Unpublished PhD dissertation, University of Amsterdam.

Pullum, G. \& Scholz, B. (2002). Empirical assessment of stimulus poverty arguments. The Linguistic Review 19, 9-50.

Rothman, J. \& Iverson, M. (20II). Poverty-of-the-stimulus and SLA epistemology: considering L2 knowledge of aspectual phrasal semantics. Language Acquisition 15, 270$3 \mathrm{I} 4$.

Rothweiler, M. (2006). The acquisition of $\mathrm{V}_{2}$ and subordinate clauses in early successive acquisition of German. In C. Lleó (ed.), Interfaces in multilingualism: acquisition, representation and processing, 93-I I 5. Amsterdam: John Benjamins.

Schwartz, B. D. (2004). On child L2 development of syntax and morphology. Lingue e Linguaggio 3, 97-I 32 .

Schwartz, B. D. \& Sprouse, R. A. (2013). Generative approaches and the poverty of the stimulus. In J. R. Herschensohn \& M. Young-Scholten (eds), The Cambridge handbook of second language acquisition, I37-58. Cambridge: Cambridge University Press.

Serratrice, L. (20I3). Cross-linguistic influence in bilingual development: determinants and mechanisms. Linguistic Approaches to Bilingualism 3, 3-25.

Slabakova, R. (2006). Is there a critical period for semantics? Second Language Research 22, I-37.

Sopata, A. (2010). V2 phenomenon in child second language acquisition. In M. T. Prior, Y. Watanabe \& S. Lee (eds), Selected Proceedings of the 2008 Second Language Research Forum: exploring SLA positions, perspectives, and practices, 2I I-28. Somerville, MA: Cascadilla Press.

Sorace, A. \& Serratrice, L. (2009). Internal and external interfaces in bilingual language development: beyond structural overlap. International Fournal of Bilingualism I3, I 95-2 I0.

Stadthagen-González, H., Gathercole, V. C. M., Pérez-Tattam, R. \& Yavas, F. (20I3). Vocabulary assessment of bilingual adults: to cognate or not to cognate. In V. C. M. Gathercole (ed.), Solutions for the assessment of bilinguals, 125-45. Bristol: Multilingual Matters.

Thomas, E. M., Williams, N., Jones, L. A., Davies, S. \& Binks, H. (2014). Acquiring complex structures under minority language conditions: bilingual acquisition of plural morphology in Welsh. Bilingualism: Language and Cognition 17, 478-94.

Thordardottir, E. (201 I). The relationship between bilingual exposure and vocabulary development. International Fournal of Bilingualism r5, 426-45.

Tran, J. (2005). Word order and verb inflection in English-speaking children's L2 acquisition of German V2. University of Hawai' $i$ Working Papers in Linguistics 36, $\mathbf{I}-35$.

Tsimpli, I.M. (20 I 4). Early, late or very late? Timing acquisition and bilingualism. Linguistic Approaches to Bilingualism 4, 283-3 I 3 .

Unsworth, S. (2005). Child L2, adult L2, child $L_{I}$ : differences and similarities. A study on the acquisition of direct object scrambling in Dutch. Unpublished $\mathrm{PhD}$ dissertation, Utrecht University.

Unsworth, S. (20I3). Assessing the role of current and cumulative exposure in simultaneous bilingual acquisition: the case of Dutch gender. Bilingualism: Language and Cognition r6, 86-i io.

Unsworth, S. (2014). Comparing the role of input in bilingual acquisition across domains. In T. Grüter \& J. Paradis (eds), Input and experience in bilingual development, I8I-20I. Amsterdam: John Benjamins. 


\section{UNSWORTH}

Unsworth, S. (in press). Quantity and quality of language input in bilingual development. In S. Montanari \& E. Nicoladis (eds), Lifespan perspectives on bilingualism. Berlin: APA / Mouton de Gruyter.

Unsworth, S., Argyri, F., Cornips, L., Hulk, A., Sorace, A. \& Tsimpli, I. (20 I 4). On the role of age of onset and input in early child bilingualism in Greek and Dutch. Applied Psycholinguistics 35, 765-805.

Unsworth, S., Gualmini, A. \& Helder, C. (2008). Children's interpretation of indefinites in negative sentences: a re-assessment of the cross-linguistic picture. Language Acquisition I5, 31 $5-28$.

van Bergen, G. \& de Swart, P. (2009). Definiteness and scrambling: where theory meets practice. In A. Schardl, M. Walkow \& M. Abdurrahman (eds), Proceedings of NELS 38 , 89-100. Amherst, MA: GSLA.

Yang, C. (2002). Knowledge and learning in natural language. Oxford: Oxford University Press.

Zdorenko, T. \& Paradis, J. (2008). The acquisition of articles in child second language English: fluctuation, transfer or both? Second Language Research 24, 227-50. 